\title{
Multi-cohort stand structure in boreal forests of northeastern Ontario: Relationships with forest age, disturbance history, and deadwood features
}

\author{
by Ben Kuttner ${ }^{1, *}$, Jay R. Malcolm and Sandy M. Smith
}

\begin{abstract}
Multi-cohort forest management (MFM) is a natural disturbance emulation strategy for boreal forests that recommends a diversification of silvicultural techniques to emulate three broad successive phases of post-fire development, termed "cohort classes". Here, for boreal mixedwood $(n=308)$ and black spruce $(n=108)$ stands of northeastern Ontario, we: 1$)$ present a multivariate approach to classify the three cohort classes based on a broad set of stand structural variables related to live-tree diameters, densities, and measures of canopy stratification and 2) investigate variation in stand age, mode of stand origin (including horse- and mechanically logged and natural-origin stands), and deadwood features among the cohort classes. In both forest types, average stem diameter distributions in cohort class 1 were normally distributed, those in class 2 showed broader normal distributions, and those in class 3 showed inverse-J distributions. Mean stand age increased with cohort class, and was positively correlated with cohort class in both forest types. Overall, variation in age and deadwood features as a function of cohort class in both forest types provided strong support for developmental aspects of our cohort classifications. Previously logged stands were primarily associated with lower cohort classes, whereas natural-origin stands were strongly associated with complex cohort class 3 stand structures, especially in mixedwoods. As it is primarily the silvicultural manipulation of stand structure that has been proposed to emulate age-related multi-cohort development, our structural cohort classification approach is particularly relevant to the application of MFM in Ontario.
\end{abstract}

Keywords: boreal forest, stand structure, cohort, multi-cohort forest management, boreal mixedwood, black spruce, forest classification, diameter distributions, tree size heterogeneity

\section{RÉSUMÉ}

Laménagement forestier multi-cohortes (MFM) est une stratégie pour imiter les perturbations naturelles des forêts boréales qui propose une diversification des techniques sylvicoles pour reproduire trois grandes phases successives de développement post-incendie, appelés « classes de cohorte ». Cet article porte sur les peuplements mixtes $(n=308)$ et dépinette noire $(n=$ 108) en forêt boréale du nord-est de l'Ontario. Pour ces forêts, 1) nous présentons une approche multivariée pour classifier les trois classes de cohorte à partir d'un large ensemble de variables structurales des peuplements liées au diamètre et à la densité des arbres vivants et aux mesures de stratification du couvert et 2) nous étudions la variation de lâge du peuplement, lorigine du peuplement (notamment les peuplements exploités avec des chevaux et mécaniquement et ceux dorigine naturelle), et les caractéristiques du bois mort entre les classes de cohorte. Dans les deux types de forêts, les diamètres moyens de tige dans la classe de cohorte 1 affichaient une distribution normale, ceux de la classe 2 avaient une distribution normale étendue et ceux de la classe 3 présentaient une distribution en forme de J inversé. Lâge moyen du peuplement augmentait avec la classe de cohorte, et montrait une corrélation positive avec la classe de cohorte dans les deux types de forêts. Dans lensemble, la variation de lâge et des caractéristiques du bois mort en fonction de la classe de cohorte dans les deux types de forêt semble supporter laspect développemental de nos classifications de cohortes. Les peuplements issus de coupes antérieures étaient surtout associés aux classes de cohortes inférieures, alors que les peuplements dorigine naturelle étaient fortement associés aux structures de peuplements complexes de classe 3 en particulier dans les forêts mixtes. Comme on propose surtout les approches sylvicoles pour imiter le développement multi-cohortes liée à lâge, notre approche de classification des cohortes basée sur les structures cadre particulièrement bien avec l'application des MFM en Ontario.

Mots-clés s : forêt boréale, structure de peuplement, cohorte, aménagement forestier multi-cohorte, forêt boréale mixte, épinette noire, classification des forêts, distribution de diamètres, hétérogénéité des dimensions d’arbres

${ }^{1}$ University of Toronto, Faculty of Forestry, 33 Willcocks St., Toronto, Ontario M5S 3B3.
* Author to whom correspondence should be sent. E-mail: ben.kuttner@utoronto.ca 


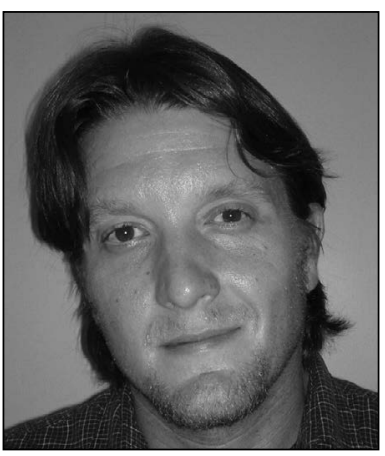

Ben Kuttner

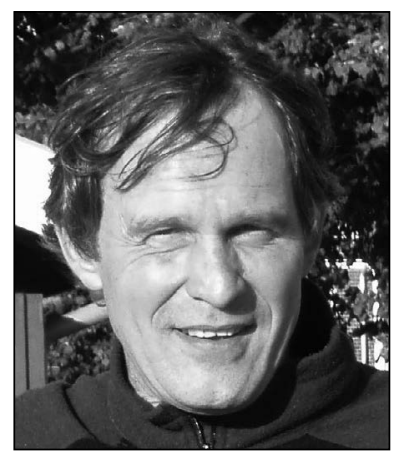

Jay R. Malcolm

\section{Introduction}

The structural complexity of boreal forests varies markedly in response to natural disturbance events, which range from high-intensity, stand-replacing wildfires to lower-intensity fire, wind, ice, and insect events (e.g., Brassard and Chen 2006). In eastern Canadian boreal forests, fire return intervals often exceed the longevity of the first post-fire cohort of trees, leading to the development of increasingly complex stand structures characterized by multiple age cohorts of trees (Gauthier et al. 2002, Bergeron et al. 2001, Groot et al. 2004). However, because of relatively short forest rotations (c. 80-100 years), traditional even-aged silvicultural approaches threaten to truncate stand development and simplify forest structure across managed boreal forest landscapes (Bergeron et al. 2001, 2007). "Multicohort forest management" (MFM) has been proposed as an alternative to the virtually exclusive use of such even-aged management in the boreal forest. The approach focuses on three broad phases of stand development following wildfire: a first cohort class of relatively even-aged stands, a second cohort class of uneven-aged stands in which the pioneer cohort is gradually being replaced by trees established in the understory, and a third cohort class of late-successional stands with multiple age cohorts of trees maintained by relatively small-scale canopy gap disturbances (Bergeron and Harvey 1997; Bergeron et al. 1999, 2002; Harvey et al. 2002).

As originally envisioned, the concept of cohort classes was used to integrate aspects of stand age, composition, and structure into three broad developmental stages (Bergeron and Harvey 1997, Bergeron et al. 1999). As a result, most cohort classification approaches have relied upon a combination of time since fire and forest composition to identify cohort classes (Harvey et al. 2002, Groot et al. 2004). Unfortunately, Ontario's Forest Resource Inventory (FRI) presents significant challenges to applying the concept. Stand ages in the FRI are based largely on tree heights interpreted from aerial imagery, and thus may represent the age of dominant trees rather than time since fire (Thompson et al. 2007, Maxie et al. 2010). Similarly, FRI stand composition is largely based on the photo-interpreted relative proportions of dominant tree species and may not accurately reflect species composition, especially in mixed species and multi-layered stands (Pinto et al. 2007, Maxie et al. 2010). Approaches to cohort classification that consider successionrelated changes in species composition are further complicated by natural variability in disturbance and successional dynamics, which can result in stands of the same age having widely

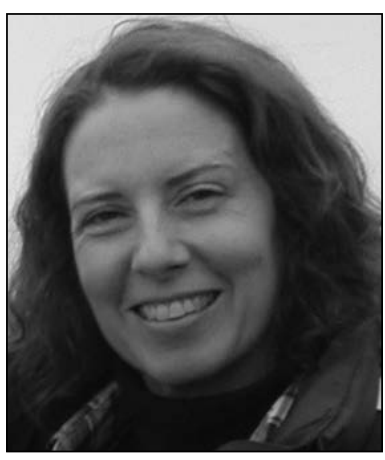

Sandy M. Smith varying compositional and structural attributes (Harvey et al. 2002, Lecomte and Bergeron 2005). These complications suggest that the classification of cohorts based upon associated structural variability could be of practical value in identifying the cohort classes. Quantitative techniques to identify the three cohorts based on within-stand measures of structural heterogeneity, such as live-tree densities and size distributions (e.g., Nguyen 2000), are of particular interest in this regard. It is also of interest to consider the extent to which variation in other structural features among cohort classes accord with the three-cohort model. For example, deadwood features are expected to vary with forest age (McElhinney et al. 2005, Bauhus et al. 2009) and hence could be used to validate the association of cohort classes that focus on the size variability, density, and canopy stratification of live trees with progressive stages of stand development (Bergeron et al. 2002, Groot et al. 2004).

Based largely on a visual examination of diameter distribution histograms, Nguyen (2000) classified multi-cohort stand structures in the Lake Abitibi region of Quebec and, a posteriori, identified several variables that appeared to be useful in characterizing the three cohort classes. Similarly, Boucher et al. (2003) visually classified stands that had regular, irregular, and inverse-J diameter distributions associated with the three cohorts (Nguyen 2000) and developed a statistical tool to predict these structures based on tree densities and diameter distributions. These initial efforts raise the question: can such structural cohort classifications be made that do not require this initial visual classification?

Here, we use live-tree data from both harvest and natural-origin stands to present a method of structural cohort classification, and examine relationships among stand age, disturbance history, and deadwood features with the three cohort classes. Our specific objectives were to: 1) develop a multivariate stand structure classification procedure that identifies the three cohort classes, 2) examine the utility of a suite of stand variables related to tree diameter, stem density, and canopy strata in identifying and classifying the three cohorts, and the extent to which they vary among the cohort classes, 3) examine the correspondence of stand age and various modes of stand origin with the three cohort classes, and 4) investigate the correspondence between cohort classes and age-related deadwood features, including downed wood and snags. Under the assumption that live-tree, multi-cohort stand structures vary characteristically with age, we hypothesized that stand age would increase with cohort class and that age-related deadwood features would differ among cohort classes. Similarly, because clearcut logging may simplify forest structure both immediately following disturbance and during subsequent stand development (Sturtevant et al. 1997, Pedlar et al. 2002), we expected that stands of harvest origin would more often be associated with lower cohort classes (1 and 2) than natural-origin stands. 


\section{Methods}

\section{Study sites}

In total, 416 study sites were used, including sites in Rowe's (1972) Northern Clay, Central Plateau, Missinaibi-Cabonga, and Superior boreal forest sections (Fig. 1). All sites were in the Ontario Ministry of Natural Resources "Lake Abitibi Ecoregion" (4E3) of northeastern Ontario (Crins et al. 2006). Mean annual precipitation in the Ecoregion ranges between $652 \mathrm{~mm}$ and $1029 \mathrm{~mm}$. Winters tend to be long and cold with heavy snowfalls of $214 \mathrm{~cm} /$ year to $313 \mathrm{~cm} /$ year, whereas summers are warm, but short. Mean annual temperature range is $-0.5^{\circ} \mathrm{C}$ to $2.5^{\circ} \mathrm{C}$ and growing season length is 167 to 185 days (Chapman and Thomas 1968, Environment Canada 1993, Mackey et al. 1996, Crins et al. 2006).

We relied primarily upon data from Ontario's Provincial Growth and Yield plot network, but established additional plots using similar sampling methods in older unlogged stands, which tended to be underrepresented in the Provincial data set. Additional deadwood and forest age data were also collected for a subset of sites $(n=75)$. Two main sampling schemes were present in the data set: "Permanent Sample Plots" in which three separate $400-\mathrm{m}^{2}$, circular plots were sampled for trees and snags $(n=50)$ and "Permanent Growth Plots" in which only one such plot was sampled for trees and snags $(n=346)$. A few sites had single $500-\mathrm{m}^{2}$ circular plots $(n=9)$ or a single $20 \times 20 \mathrm{~m}(n=2)$ or $32 \times 32 \mathrm{~m}$ plot $(n=9)$. Data collection methodologies were consistent for the various plots (see Hayden et al. 1995, Hayden 2003): all trees $>2.5$ $\mathrm{cm}$ in diameter at breast height $(\mathrm{DBH})$ and standing dead wood (snags) $>10.0 \mathrm{~cm} \mathrm{DBH}$ were inventoried. For sites that had been measured more than once, we used only the most recent data.

Based on regionally defined algorithms applied to dominant and co-dominant trees in the plots, three forest types ("standard forest units") were represented in our sample (Watt et al. 2003): 1) mixed conifer/deciduous stands comprised largely of white birch, trembling aspen, black and white spruce and balsam fir on

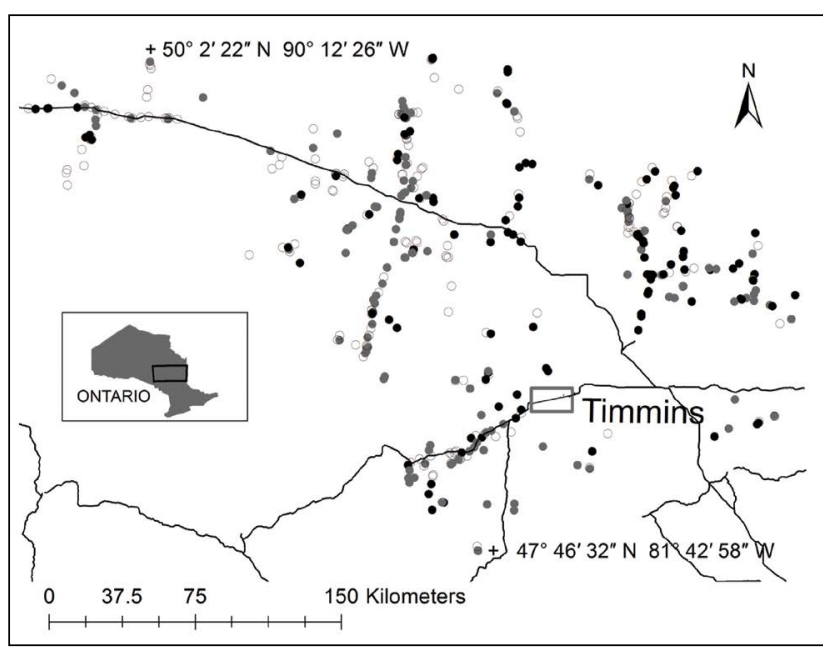

Fig. 1. Map of boreal mixedwood $(n=308 ; 0=S F 1$ and - MW2 standard forest unit types) and black spruce $(n=108$; - = SB1) study sites in northeastern Ontario. Black lines indicate major roads. Inset map is of Ontario with black outline showing study area extent. moist, medium loamy to clayey soils (MW2; $n=129), 2$ ) mixed conifer-dominated stands of black spruce, white spruce (Picea glauca [Moench] Voss), balsam fir (Abies balsamea [L.] Mill.), trembling aspen (Populus tremuloides Michx.), eastern whitecedar (Thuja occidentalis L.), and white birch (Betula papyrifera Marsh.) growing on moist sandy to clayey soils (SF1; $n=179$ ), and 3) black spruce (Picea mariana [Mill.] BSP) stands growing on wet, deep organic soils or on moist, peaty-phase mineral soils in lower slope positions, (SB1; $n=108)$. Based on the plot measurements of live trees $>2.5 \mathrm{~cm} \mathrm{DBH}$, species composition in the two mixedwood forest types varied widely; percent conifer composition (stems $>2.5 \mathrm{~cm} \mathrm{DBH}$, by basal area) ranged from $31 \%$ to $79 \%$ (mean $=51 \%$ ) for MW2 stands and from $30 \%$ to $100 \%$ (mean $=86 \%$ ) for SF1 stands. For SB1 stands, conifer composition ranged between 90 and 100\% (mean $=99 \%$ ).

Following protocols for the provincial growth plot network (Miller 1994, Hayden et al. 1995), most stand ages were estimated from mean ages of dominant and co-dominant trees in the stands, as measured by use of tree increment core samples. For a small subset of plots ( $n=11$ MW2 stands and $n=3 \mathrm{SB} 1$ stands), these ages were missing and FRI ages were used. MW2 stands ranged between 27 and 155 years old (mean $=70$ years), SF1 stands between 37 and 220 years old (mean $=72$ years), and SB1 stands between 26 and 191 years old (mean $=86$ years).

Previously harvested and natural-origin stands were represented in all three forest types. Disturbance history, however, could only be determined with confidence for a subset of the plots based on detailed historical reconstructions (S. Vasiliauskas, Ontario Ministry of Natural Resources, Northeast Science and Information, personal communication, March 23, 2006). Of these, the MW2 sample included 28 natural-origin stands, 18 that were horse-logged clearcut, and 2 that were clearcut with use of skidders; the SF1 sample included 41 naturalorigin stands, 16 horse-logged, and 20 mechanically logged stands, and the SB1 sample included 27 natural-origin stands, 14 horse-logged, and 6 mechanically logged stands. Based on stand ages and the long history of fire suppression in the study area, the majority of stands of undetermined origin were likely of harvest origin.

Exploratory multivariate analyses (not presented here) showed that SF1 and MW2 forest types shared similar patterns of structural variation based on tree diameters and densities and canopy strata-related variables (see Kuttner 2006 for additional details); hence, we combined the two types for analysis into a "mixedwood" analysis group. SB1 sites were identified as a separate group in these analyses, presumably due to the relatively small sizes of black spruce trees on wet, organic and peaty-phase sites compared to other tree species found on more upland sites in boreal mixedwoods, and hence were analyzed separately.

\section{Classification variables}

Following Nguyen (2000) and Boucher et al. (2003), we derived a suite of structural variables that reflected variation in the diameter distributions of live trees and hence might reflect variation related to the cohort classes. In addition, we used variables that reflected variation in tree densities as a function of tree diameter and variation in the vertical stratification of the canopy. Counts of stems of live trees $>2.5 \mathrm{~cm}$ DBH were binned into $2-\mathrm{cm}$ diameter classes and used to calculate diameter class richness, maximum diameter, and the range of diameter classes. In addition, diameter class diversity was calculated using the Shannon-Wiener diversity index and diameter class evenness 
was calculated using Pielou's formula (Legendre and Legendre 1998). A variant of the coefficient of skewness $\left(\alpha_{3}\right)$ was used to quantify asymmetry of the diameter distributions:

$$
\alpha_{3}=\left[\Sigma\left(\mathrm{x}_{\mathrm{i}}-\overline{\mathrm{x}}\right)^{3} /(\mathrm{n}-1)\right] / \mathrm{s}_{\mathrm{x}}^{3}
$$

where $x_{i}$ is the number of trees in the $i$ th diameter class, $\bar{\chi}=$ mean stem diameter class, $n=$ number of diameter classes, and $s_{x}$ is the standard deviation of stem diameter classes (Boucher et al. 2003). The coefficient of variation of diameter classes was also calculated (Legendre and Legendre 1998, Boucher et al. 2003).

Two-parameter Weibull probability density functions were fit to the diameter distribution data (using the CAPABILITY procedure in SAS v. 8.02) and both parameters were included as classification variables. The Weibull shape parameter describes the shape of the distribution, which varies from negative exponential, to log-normal, to normal; Weibull scale relates to average tree size as it represents the diameter class at which $63.2 \%$ of the stems have accumulated (Abernethy 1996).

Trees were assigned to broad size classes according to the following size thresholds: small $(\leq 9.0 \mathrm{~cm} \mathrm{DBH})$, medium (9-21 cm DBH), and large (>21 cm DBH) (Nguyen 2000). Different size classes were used for black spruce trees in SB1 stands: $\leq 9 \mathrm{~cm}, 9-16 \mathrm{~cm}$, and $>16 \mathrm{~cm} \mathrm{DBH}$. Overall tree density (stems/ha) and density by size class was calculated for each plot and relative densities of large, medium, and small trees also were calculated (the number of trees/ha in the size classes divided by total tree density). For SB1 sites, relative densities by size class were calculated just for black spruce trees.

At the time of sampling, live trees were assigned to one of the following seven crown classes: emergent, dominant, co-dominant, intermediate, overtopped-suppressed, understory, and open understory (Hayden et al. 1995). These crown classes were converted to five numerical classes: 1 = emergent, 2 = dominant, $3=$ co-dominant, $4=$ intermediate and $5=$ understory (which included understory, open understory, and overtopped-suppressed crown classes). Crown class richness measured the number of unique values of these crown strata; crown class diversity and evenness were calculated using the Shannon-Wiener diversity index and Pielou's formula, respectively.

The net effect was 16 classification variables for each plot: diameter class richness, evenness, diversity, skewness, coefficient of variation, range, and maximum, Weibull shape and scale, crown class richness, evenness, and diversity, total tree density, and the relative densities of small, medium, and large trees. For sites that had multiple $400-\mathrm{m}^{2}$ plots, variables were calculated for the individual plots and mean values across the plots were used in analyses. The final set of plots used for analyses was arrived at by first examining variables for outliers and other anomalous values. Sample sizes provided above are after such exclusions ( $~ 5 \%$ to $10 \%$ of candidate sites in each forest type) had taken place.

\section{Deadwood variables}

Snags $>10 \mathrm{~cm}$ DBH were inventoried to species and assigned to a decay class using a five-class system (Hayden et al. 1995, Hayden 2003). Total snag density (stems/ha) was calculated for snags in decay classes 1 to 3 (termed "fresh" snags) and decay classes 4 and 5 (termed "well-decomposed" snags). In addition, these categories were further subdivided into size classes: small (>10-15 cm DBH), medium (>15-25 cm DBH), and large $(>25 \mathrm{~cm} \mathrm{DBH})$ for a total of eight snag-related variables (i.e., the total density and densities in each size class).

For the subset of plots $(n=75)$ in which downed wood (DWD) was measured, three 45-m long lines were extended from the plot centre and oriented at $120^{\circ}$ to one another. Along the lines, the diameters of all logs $>7.5 \mathrm{~cm}$ in diameter at the point of intersection with the line were measured and assigned a decay class between 1 and 5 (Maser et al. 1979, Hayden 2003). Volumes of DWD by decay class (Marshall et al. 2000) were calculated for each sampled site, and decay classes 1 and 2 and decay classes 3 to 5 were combined to provide measurements of early- and late-decay downed wood, respectively.

\section{Statistical methods}

\section{Principal component analysis and cluster analyses}

Ordination followed by cluster analysis was used to classify cohort types. First, a principal component analysis (PCA) on the correlation matrix of the 16 variables was undertaken to characterize main gradients of structural complexity. Sites were then clustered according to scores on the PCA axes using Ward's minimum variance clustering method, and the number of clusters was controlled a priori (Legendre and Legendre 1998). The number of PCA axes to include in cluster analyses was determined by the broken stick PCA stopping rule (PeresNeto et al. 2005).

Results that used between two and six clusters were examined and combinations of clusters were used to arrive at the three-class cohort structure classification consistent with theoretical expectations, that is, classes showing diameter distributions that were on average (i.e., according to curves plotted using each cluster's and/or combined clusters' mean Weibull parameters) relatively normal and bell-shaped (cohort class 1), broader and flatter and bell-shaped (cohort class 2), and inverse-j (cohort class 3) (Nguyen 2000). Various possible cluster combinations were evaluated using PCA biplots in which various site attributes were symbolized, such as age and density, and by examining resulting cohort assignments in the context of field observations and previous studies (Nguyen 2000, Boucher et al. 2003). PCA analyses were undertaken using CANOCO for Windows (v. 4.5); other analyses were undertaken in SAS (v. 8.02).

\section{Comparisons of classification variables among the cohort classes}

As a non-parametric procedure for testing for differences among the three cohort classes, the structure variables were rank-transformed and their mean ranks compared among the cohort classes using analysis of variance and Tukey's range tests.

\section{Classification functions}

Given the cohort class assignments, based on the approaches of Nguyen (2000) and Boucher et al. (2003), we developed classification functions by use of discriminant analysis with thresholds to enter and stay in models set to $p=0.15$.

\section{Stand age and disturbance history comparisons}

Values of stand age were rank-transformed and their ranked values compared among the structure classes via analysis of variance and Tukey's range tests. In addition, non-parametric 
Spearman's correlations of stand age with structure class were calculated. Abundances of the structure classes among the three disturbance histories and in three broad age classes $(<50$ years, $50-80$ years, $>80$ years of age) were tabulated and tested via likelihood ratio tests (Sokal and Rolf 1995).

Comparisons of deadwood variables among the cohort classes Similar to the non-parametric stand age analyses, deadwood variables were rank-transformed and their mean ranks compared among the cohort classes via analysis of variance and Tukey's studentized range test.

\section{Results}

\section{Mixedwood ordination and clustering results}

Clustering was performed on site scores from the first two principal component axes (Fig. 2). Exploratory analyses based on three clusters performed poorly: one of the three clusters included a small number of sites and another relatively large cluster had sites with both irregular and inverse-J diameter distributions. Consequently, we used a four-cluster solution and two of these clusters (clusters 3 and 4) were combined because they showed the most similar average diameter distribution shapes (Fig. 3).

The first PCA axis, which explained $37 \%$ of the total variation, represented a tree density and size gradient, with plots on the right having relatively high Weibull scale scores, large percentages of large and medium trees, and low total tree densities (Fig. 2). Diameter class diversity also was strongly positively associated with this axis. The second axis explained an additional $31 \%$ of the total variance and appeared to represent a gradient of diameter distribution shapes as reflected in variation in Weibull shape, diameter class richness and range, and coefficient of variation. Sites with relatively normal diameter distributions had low scores on the axis and sites with inverse-J distributions had high scores.

The majority of cohort class 3 sites had positive scores on axis 2 and, to a lesser extent, on axis 1. Diameter class diversity, richness, range, coefficient of variation, and the relative density of large trees were all positively associated with this class. Conversely, cohort class 1 sites had low scores on both axes and were positively associated with total tree density, the relative density of small trees, and Weibull shape. Cohort class 2 sites tended to have intermediate scores on axis 1 , but low scores on axis 2 . They were strongly associated with the relative density of medium sized trees, and were primarily differentiated from cohort class 1 on the basis of other size related variables (e.g., Weibull scale, DBH range, density of large trees) and from cohort class 3 on the basis of diameter distribution pattern-related variables (e.g., Weibull shape, coefficient of variation, and skewness). Cohort class 2 sites also tended to be highly associated with crown class diversity and evenness.

\section{Black spruce ordination and clustering results}

Clustering was performed on the first four PCA axis scores (Fig. 2). Similar to the mixedwoods, a four-cluster solution was used in which two clusters were combined into one (Fig. 2). However, in this case clusters 2 and 4 were combined to represent cohort class 2. Both had bell-shaped curves on average, and relative to cluster 1, broader and flatter bell-shaped curves (Fig. 3). Only cluster 3 displayed an inverse-J diameter distribution (Fig. 3). Cluster 3 also was the most strongly related to diameter class range, richness, and diversity as expected for cohort class 3 structure (Nguyen 2000, Boucher et al. 2006; Fig. 2).

As in the mixedwood PCA, the first principal component axis represented a tree size and density gradient to which total density, Weibull scale, and relative densities of small and large trees were strongly related, and explained an even higher proportion of the total variance than in the mixedwood analysis (42\%; Fig. 2). The second principal component described variation in diameter distribution shape as judged by correlations with Weibull shape and the coefficient of variation. However, the second principal component was not as strong as in the mixedwood analysis ( $21 \%$ of the total variance).

Cohort class 3 black spruce sites had mostly positive scores on both axes, similar to the mixedwood results. These sites also were strongly positively associated with diameter class richness, maximum diameter class, diameter class range, and diversity and, to a lesser extent, coefficient of variation and the density of large trees (Fig. 2). Cohort class 1 sites again were negatively associated with those variables and positively associated with the density of small trees and total tree density, which separated them from cohort class 2 sites. Cohort class 2 black spruce sites were almost all negatively loaded on the second principal component axis, but shared a similar range of variation with cohort class 3 sites along the first (i.e., size related) axis. Cohort class 2 sites were most strongly associated with the density of medium-sized trees. Contrary to mixedwood results, vectors for crown class diversity and evenness in the black spruce forests were more strongly related to cohort class 3 than class 2 , although they were relatively short.

\section{Classification variables as a function of cohort class}

For both the mixedwood and black spruce forest types, all variables except crown class richness differed significantly among the cohort classes and most were highly significant (Tables 1 and 2). Tukey's tests indicated that for most variables, all three pair-wise comparisons also were significant ( 8 and 9 of the 16 variables for mixedwoods and black spruce, respectively; Tables 1 and 2).

\section{Discriminant function analyses}

For both forest types, 9 of the 16 variables were selected in the discriminant analysis (Tables 3 and 4). Five were common to both forest types: the relative density of medium-sized trees, total tree density, coefficient of variation, crown class evenness, and Weibull shape. Classification variables unique to mixedwoods were, in order of significance, maximum diameter class, the relative density of small trees, diameter class richness, and diameter distribution skewness. For black spruce, they were diameter class diversity, crown class diversity, diameter class evenness, and the relative density of large black spruce trees. Classification success was relatively high in both forest types. Error counts for the mixedwood analysis group were $9 \%, 10 \%$, and $18 \%$ for classes 1,2 , and 3, respectively; corresponding numbers for black spruce stands were $0 \%, 13 \%$, and $6 \%$. In both forest types, classification errors were more common for cohort classes 2 and 3 than for class 1 .

\section{Stand age and disturbance history comparisons}

Stand age increased significantly $(p<0.0001)$ with structure class in both forest types. Spearman's correlations of stand age with structure class were also positive and highly significant for both the mixedwood $\left(r_{\mathrm{s}}=0.57 ; p<0.0001\right)$ and spruce forest types $\left(r_{\mathrm{s}}=0.44 ; p<0.0001\right)$. According to Tukey's test, 

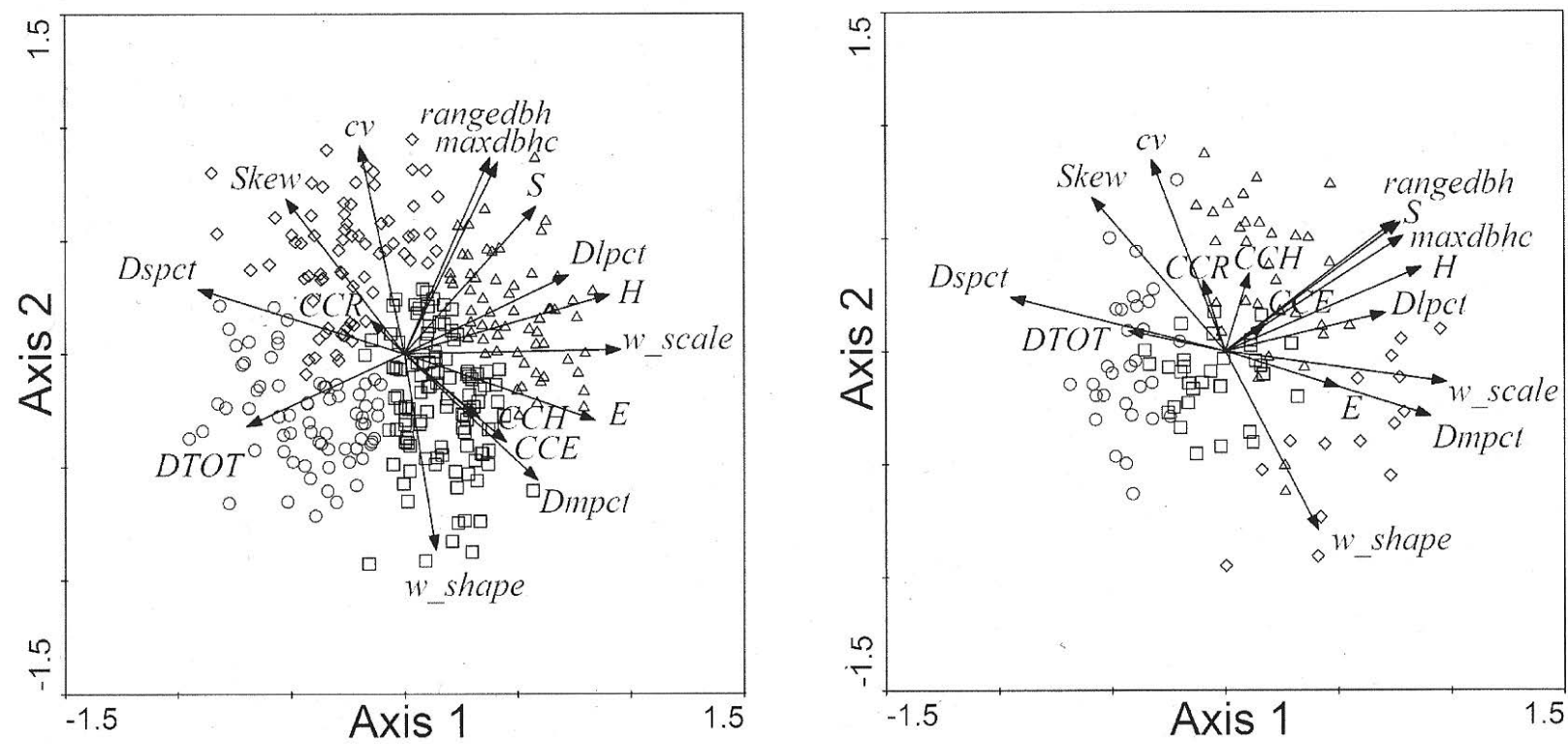

Fig. 2. Principal component analysis of sixteen structural classification variables for boreal mixedwood (left; $n=308$ ) and black spruce (right; $n=108$ ) sites in northeastern Ontario, with results of the cluster analyses shown (cluster $1=0$; cluster $2=\square$; cluster $3=\Delta$; and cluster $4=\diamond$ ). See Tables 1 and 2 for acronyms of the 16 classification variables; see text for details of the cluster analyses.

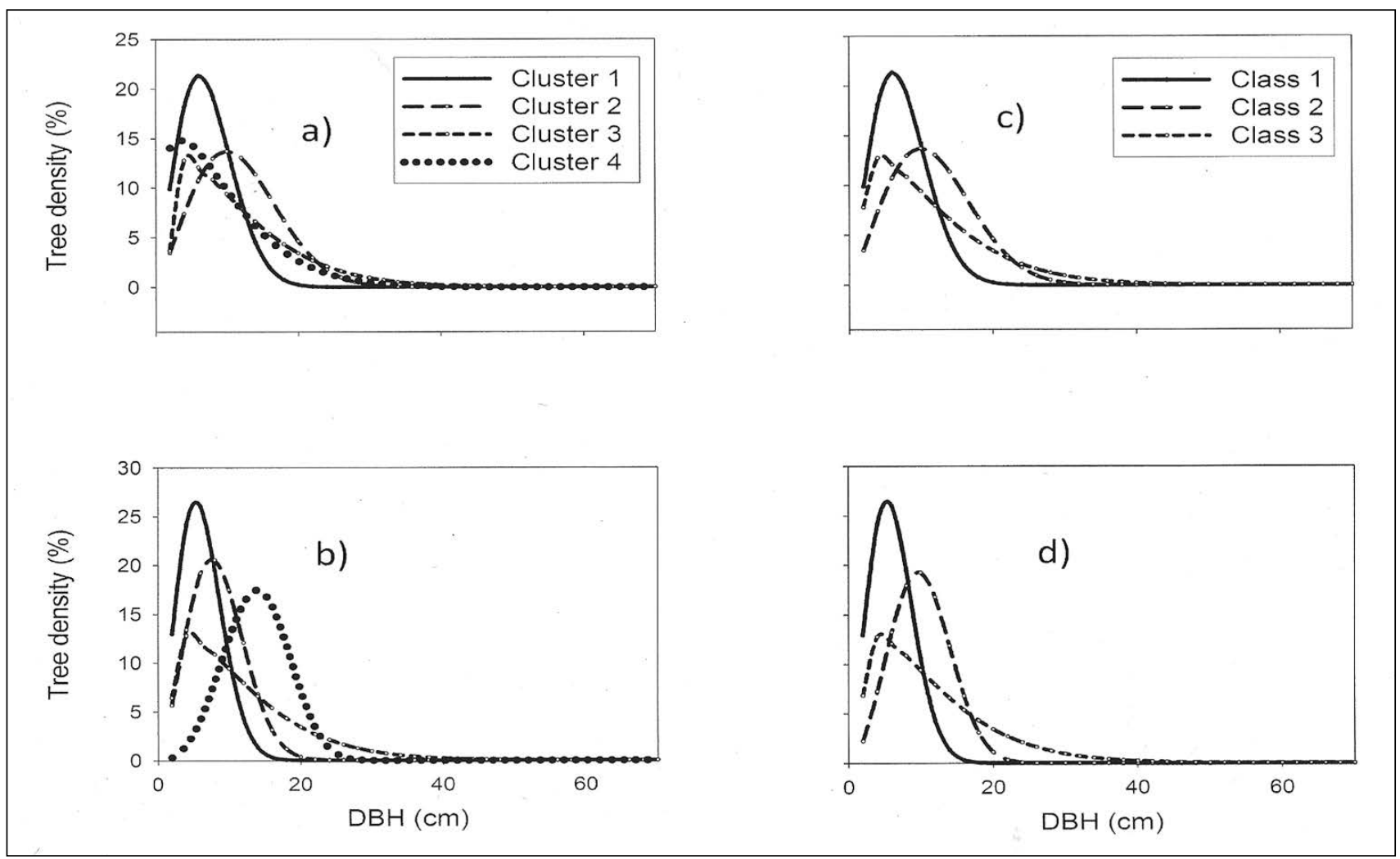

Fig. 3. Two-parameter Weibull curves based on the mean parameter values from Weibull functions fit to live tree diameter distributions in four forest structure clusters of boreal mixedwood (a) and black spruce (b) stands in northeastern Ontario as determined from combined principal component and cluster analyses (see text for details). The final cohort classes were defined by combining clusters 3 and 4 for mixedwood sites (c) and clusters 2 and 4 for black spruce sites (d). 
Table 1. Means of forest structure variables in cohort classes of boreal mixedwood stands in northeastern Ontario $(n=308)$ and results from Analysis of Variance and Tukey's tests comparing the rank-transformed variables among classes.

\begin{tabular}{|c|c|c|c|c|c|c|c|c|c|c|}
\hline \multirow[b]{2}{*}{ Variable $^{a}$} & \multicolumn{2}{|c|}{$\begin{array}{l}\text { Cohort class } 1 \\
\qquad(n=68)\end{array}$} & \multicolumn{2}{|c|}{$\begin{array}{c}\text { Cohort class } 2 \\
\quad(n=109)\end{array}$} & \multicolumn{2}{|c|}{$\begin{array}{l}\text { Cohort class } 3 \\
\qquad(n=131)\end{array}$} & \multirow{2}{*}{$\begin{array}{l}\text { ANOVA } \\
\text { P-value }\end{array}$} & \multirow{2}{*}{$\begin{array}{c}\text { Class } 1 \\
\text { vs. } \\
\text { Class } 2^{\text {b }}\end{array}$} & \multirow{2}{*}{$\begin{array}{c}\text { Class } 2 \\
\text { vs. } \\
\text { Class } 3^{\text {b }}\end{array}$} & \multirow{2}{*}{ 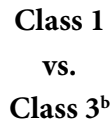 } \\
\hline & Mean & Std. dev. & Mean & Std. dev. & Mean & Std. dev. & & & & \\
\hline CCE & 0.79 & 0.11 & 0.83 & 0.09 & 0.74 & 0.15 & $<0.0001$ & - & * & - \\
\hline $\mathrm{CCH}$ & 1.11 & 0.15 & 1.14 & 0.15 & 1.04 & 0.24 & 0.0020 & - & * & - \\
\hline CCR & 4.09 & 0.33 & 3.99 & 0.45 & 4.06 & 0.57 & 0.2816 & - & - & - \\
\hline DTOT & 4836 & 1807 & 2347 & 762 & 1952 & 1034 & $<0.0001$ & * & * & * \\
\hline DlpctSb & 0.94 & 1.40 & 8.38 & 5.69 & 18.14 & 13.77 & $<0.0001$ & * & * & * \\
\hline DmpctSb & 27.44 & 11.54 & 54.19 & 14.33 & 30.62 & 14.48 & $<0.0001$ & * & * & - \\
\hline DspctSb & 71.63 & 11.74 & 37.43 & 13.87 & 51.24 & 21.17 & $<0.0001$ & * & * & * \\
\hline $\mathrm{E}$ & 0.81 & 0.06 & 0.89 & 0.03 & 0.85 & 0.08 & $<0.0001$ & * & * & * \\
\hline $\mathrm{H}$ & 1.86 & 0.20 & 2.28 & 0.15 & 2.30 & 0.27 & $<0.0001$ & * & - & * \\
\hline$S$ & 10.05 & 1.91 & 13.15 & 1.91 & 15.14 & 2.43 & $<0.0001$ & * & * & * \\
\hline Skew & 1.18 & 0.70 & 0.70 & 0.59 & 1.46 & 0.89 & $<0.0001$ & * & * & * \\
\hline $\mathrm{cV}$ & 52.57 & 9.39 & 52.96 & 12.64 & 76.10 & 18.73 & $<0.0001$ & - & * & * \\
\hline $\operatorname{maxDBHc}$ & 22.77 & 5.05 & 30.56 & 5.98 & 42.54 & 8.93 & $<0.0001$ & * & * & * \\
\hline rangeDBH & 20.77 & 5.05 & 27.98 & 6.15 & 40.20 & 9.00 & $<0.0001$ & * & * & * \\
\hline w_scale & 8.33 & 1.32 & 13.28 & 1.92 & 13.52 & 4.59 & $<0.0001$ & * & - & * \\
\hline w_shape & 2.11 & 0.37 & 2.18 & 0.67 & 1.54 & 0.40 & $<0.0001$ & - & * & * \\
\hline
\end{tabular}

${ }^{a}$ Crown class evenness (CCE), diversity (CCH), richness (CCR), total tree density (DTOT), the relative densities of small (Dspct), medium (Dmpct), and large (Dlpct) trees, diameter class richness (S), evenness (E), diversity $(\mathrm{H})$, skewness (Skew), coefficient of variation (cv), range (rangeDBH), maximum diameter class (maxDBHc), and Weibull shape (w_shape) and scale parameters (w_scale). See text for detailed variable descriptions.

${ }^{\mathrm{b}}$ Results from Tukey's range tests where “»” indicates a significant difference at $\alpha=0.05$.

Table 2. As Table 1 except that results are for black spruce sites $(n=108)$.

\begin{tabular}{|c|c|c|c|c|c|c|c|c|c|c|}
\hline \multirow[b]{2}{*}{ Variable $^{a}$} & \multicolumn{2}{|c|}{$\begin{array}{l}\text { Cohort class } 1 \\
\qquad(n=30)\end{array}$} & \multicolumn{2}{|c|}{$\begin{array}{c}\text { Cohort class } 2 \\
\quad(n=46)\end{array}$} & \multicolumn{2}{|c|}{$\begin{array}{l}\text { Cohort class } 3 \\
\quad(n=46)\end{array}$} & \multirow{2}{*}{$\begin{array}{l}\text { ANOVA } \\
\text { P-value }\end{array}$} & \multirow{2}{*}{$\begin{array}{c}\text { Class } 1 \\
\text { vs. } \\
\text { Class } 2^{\mathrm{b}}\end{array}$} & \multirow{2}{*}{$\begin{array}{l}\text { Class } 2 \\
\text { vs. } \\
\text { Class } 3^{\text {b }}\end{array}$} & \multirow{2}{*}{$\begin{array}{c}\text { Class } 1 \\
\text { vs. } \\
\text { Class } 3\end{array}$} \\
\hline & Mean & Std. dev. & Mean & Std. dev. & Mean & Std. dev. & & & & \\
\hline CCE & 0.78 & 0.09 & 0.82 & 0.08 & 0.87 & 0.07 & 0.0008 & - & * & * \\
\hline $\mathrm{CCH}$ & 1.05 & 0.12 & 1.11 & 0.12 & 1.15 & 0.11 & 0.0071 & - & - & * \\
\hline CCR & 3.87 & 0.51 & 3.91 & 0.29 & 3.82 & 0.42 & 0.4019 & - & - & - \\
\hline DTOT & 3931 & 1858 & 2972 & 1117 & 2517 & 639 & 0.0031 & - & - & * \\
\hline DlpctSb & 0.70 & 1.08 & 13.44 & 19.65 & 16.52 & 8.29 & $<0.0001$ & * & * & * \\
\hline DmpctSb & 17.19 & 6.86 & 44.57 & 13.39 & 35.97 & 11.24 & $<0.0001$ & * & * & * \\
\hline DspctSb & 82.11 & 7.34 & 41.99 & 23.53 & 47.51 & 13.05 & $<0.0001$ & * & - & * \\
\hline $\mathrm{E}$ & 0.83 & 0.04 & 0.89 & 0.03 & 0.89 & 0.04 & $<0.0001$ & * & - & * \\
\hline $\mathrm{H}$ & 1.68 & 0.12 & 1.99 & 0.16 & 2.16 & 0.12 & $<0.0001$ & * & * & * \\
\hline s & 7.86 & 1.45 & 9.49 & 1.72 & 11.23 & 1.18 & $<0.0001$ & * & * & * \\
\hline Skew & 0.84 & 0.34 & 0.15 & 0.33 & 0.55 & 0.50 & $<0.0001$ & * & * & * \\
\hline $\mathrm{cv}$ & 48.80 & 5.62 & 41.59 & 8.27 & 55.26 & 8.54 & $<0.0001$ & * & * & * \\
\hline $\operatorname{maxDBHc}$ & 16.33 & 3.51 & 20.58 & 5.08 & 23.81 & 3.19 & $<0.0001$ & * & * & * \\
\hline rangeDBH & 14.33 & 3.51 & 18.07 & 4.63 & 21.77 & 3.19 & $<0.0001$ & * & * & * \\
\hline w_scale & 6.97 & 0.66 & 11.39 & 3.29 & 10.98 & 1.57 & $<0.0001$ & * & - & * \\
\hline w_shape & 2.24 & 0.26 & 2.75 & 0.65 & 2.00 & 0.38 & $<0.0001$ & * & * & * \\
\hline
\end{tabular}

${ }^{a}$ Relative densities of small (DspctSb), medium (DmpctSb), and large (DlpctSb) black spruce trees; see Table 1 for other variable descriptions.

${ }^{\mathrm{b}}$ Results from Tukey's range tests where “*” indicates a significant difference at $\alpha=0.05$. 
Table 3. Results of stepwise discriminant analysis to predict cohort class membership for boreal mixedwood $(n=308)$ and black spruce $(n=108)$ sites in northeastern Ontario. See Tables 1 and 2 for variable descriptions.

\begin{tabular}{|c|c|c|c|c|c|}
\hline \multirow[b]{2}{*}{ Forest type } & \multirow[b]{2}{*}{ Analysis variable } & \multicolumn{2}{|c|}{ Marginal tests ${ }^{\mathrm{a}}$} & \multicolumn{2}{|c|}{ Conditional tests ${ }^{a}$} \\
\hline & & Partial R-square & $\operatorname{Pr}>F$ & R-square ${ }^{2}$ & $\operatorname{Pr}>F$ \\
\hline \multirow[t]{9}{*}{ Mixedwood } & $\operatorname{maxDBHc}$ & 0.55 & $<0.0001$ & 0.55 & $<0.0001$ \\
\hline & Dmpct & 0.43 & $<0.0001$ & 0.42 & $<0.0001$ \\
\hline & DTOT & 0.49 & $<0.0001$ & 0.25 & $<0.0001$ \\
\hline & $\mathrm{cV}$ & 0.37 & $<0.0001$ & 0.14 & $<0.0001$ \\
\hline & Dspct & 0.36 & $<0.0001$ & 0.09 & $<0.0001$ \\
\hline & CCE & 0.08 & $<0.0001$ & 0.05 & 0.0005 \\
\hline & w_shape & 0.27 & $<0.0001$ & 0.02 & 0.0487 \\
\hline & S & 0.45 & $<0.0001$ & 0.02 & 0.0434 \\
\hline & Skew & 0.17 & $<0.0001$ & 0.02 & 0.1071 \\
\hline \multirow[t]{9}{*}{ Black spruce } & $\mathrm{H}$ & 0.64 & $<0.0001$ & 0.64 & $<0.0001$ \\
\hline & DmpctSb & 0.51 & $<0.0001$ & 0.37 & $<0.0001$ \\
\hline & $\mathrm{cV}$ & 0.36 & $<0.0001$ & 0.27 & $<0.0001$ \\
\hline & CCE & 0.14 & 0.0004 & 0.13 & 0.001 \\
\hline & DTOT & 0.16 & 0.0001 & 0.10 & 0.0055 \\
\hline & $\mathrm{CCH}$ & 0.11 & 0.0026 & 0.05 & 0.0614 \\
\hline & E & 0.37 & $<0.0001$ & 0.06 & 0.0562 \\
\hline & w_shape & 0.31 & $<0.0001$ & 0.07 & 0.0241 \\
\hline & DlpctSb & 0.18 & $<0.0001$ & 0.06 & 0.0558 \\
\hline
\end{tabular}

${ }^{a}$ Marginal tests are for each variable in isolation, whereas conditional tests are from stepwise discriminant analysis in which variables above the one in question were already entered into the model.

Table 4. Parameter estimates from discriminant classification functions used to predict membership in cohort classes of increasing structural complexity for mixedwood $(n=308)$ and black spruce $(n=108)$ sites in northeastern Ontario. See Tables 1 and 2 for variable descriptions.

\begin{tabular}{|c|c|c|c|c|}
\hline Forest type & Parameter & $\begin{array}{c}\text { Cohort } \\
\text { class } 1\end{array}$ & $\begin{array}{c}\text { Cohort } \\
\text { class } 2\end{array}$ & $\begin{array}{c}\text { Cohort } \\
\text { class } 3\end{array}$ \\
\hline \multirow[t]{9}{*}{ Mixedwood } & $\begin{array}{l}\text { Constant } \\
\text { maxDBHc }\end{array}$ & $\begin{array}{c}-361.210 \\
1.461\end{array}$ & $\begin{array}{c}-362.853 \\
1.259\end{array}$ & $\begin{array}{c}-361.702 \\
1.430\end{array}$ \\
\hline & Dmpct & 1.533 & 1.703 & 1.462 \\
\hline & DTOT & -0.004 & -0.005 & -0.005 \\
\hline & $\mathrm{CV}$ & 1.258 & 1.502 & 1.534 \\
\hline & Dspct & 3.322 & 3.136 & 3.033 \\
\hline & $\mathrm{CCE}$ & 132.549 & 129.494 & 126.076 \\
\hline & w_shape & 87.710 & 87.038 & 89.501 \\
\hline & S & 9.026 & 9.328 & 9.545 \\
\hline & Skew & -15.918 & -14.804 & -14.247 \\
\hline \multirow[t]{10}{*}{ Black spruce } & Constant & -2283 & -2417 & -2507 \\
\hline & $\mathrm{H}$ & 651.758 & 671.461 & 696.788 \\
\hline & DmpctSb & -5.758 & -5.574 & -5.653 \\
\hline & $\mathrm{CV}$ & 24.144 & 24.732 & 25.300 \\
\hline & CCE & 160.171 & 158.779 & 178.520 \\
\hline & DTOT & 0.006 & 0.005 & 0.004 \\
\hline & $\mathrm{CCH}$ & 112.636 & 126.868 & 123.487 \\
\hline & E & 1128 & 1164 & 1149 \\
\hline & w_shape & 535.531 & 545.285 & 553.061 \\
\hline & DlpctSb & -7.456 & -7.561 & -7.742 \\
\hline
\end{tabular}

stand age was significantly different among the three individual cohort classes for mixedwoods. For spruce, however, the difference in mean stand ages between cohort classes 2 and 3 was not significant. The range of stand ages for each cohort class revealed considerable age overlap among classes in both forest types. Cohort class membership in mixedwoods was influenced by age in accord with expectations: the vast majority of sites in cohort class 1 were $<50$ years old, and most sites 50 to 80 years old and $>80$ years old were associated with cohort classes 2 and 3 , respectively (Table 5). A similar pattern held in black spruce sites, but ages were not as strongly associated with cohort classes. For the black spruce forest, most sites in cohort class 1 were $<50$ years old, but a greater proportion of cohort class 1 sites were in the two older age classes. Most black spruce sites with cohort class 2 structure were $>80$ years old, but 18 of the 46 cohort class 2 sites were associated with either the 50-80 year or $<50$ year-old age classes (in equal proportions). The overwhelming majority of cohort class 3 sites were in stands $>80$ years of age.

Stand age estimates also ranged widely within, and overlapped among, disturbance history types in both forest types (Table 5). We speculate that some increment cores were from residual trees that predated disturbances in previously logged sites and may have influenced these results. Mean ages by disturbance type, however, indicated that mechanically logged sites tended to be younger than horse-logged sites and that natural stands tended to be older than both harvest origin stand types, as expected (Table 5). 
Table 5. Stand ages (in years) derived from tree increment core data for boreal mixedwood and black spruce study sites in northeastern Ontario by disturbance type (mechanically logged: $\mathrm{ML}$; horse-logged: HL; and unlogged: UL) and age class (stand age $<50,50-80$, and $>80$ years). The number of sites ( $n$ ) in the three cohort classes is also shown for the three disturbance types and age classes.

\begin{tabular}{|c|c|c|c|c|c|c|c|c|c|}
\hline & & \multicolumn{4}{|c|}{ Mixedwood } & \multicolumn{4}{|c|}{ Black spruce } \\
\hline & & $\mathbf{M L}^{\mathrm{a}}$ & $H^{\mathrm{a}}$ & $\mathbf{U L}^{\mathrm{a}}$ & All sites ${ }^{b}$ & $M^{a}$ & $H^{\mathrm{a}}$ & $\mathbf{U L}^{\mathrm{a}}$ & All sites ${ }^{b}$ \\
\hline \multirow[t]{5}{*}{ Cohort class 1} & Mean \pm SE & $36 \pm 3$ & $61 \pm 11$ & $81 \pm 22$ & $45 \pm 3$ & $63 \pm 9$ & $71 \pm 15$ & $101 \pm 14$ & $61 \pm 5$ \\
\hline & $n<50$ years & 8 & 1 & 1 & 50 & 2 & 2 & 0 & 12 \\
\hline & $n$ 50-80 years & 0 & 1 & 1 & 12 & 1 & 0 & 0 & 10 \\
\hline & $n>80$ years & 0 & 1 & 2 & 6 & 2 & 2 & 3 & 8 \\
\hline & range & $26-45$ & $45-81$ & $42-138$ & $26-138$ & $42-85$ & $44-98$ & $81-127$ & $26-127$ \\
\hline \multirow[t]{5}{*}{ Cohort class 2} & Mean \pm SE & $59 \pm 8$ & $73 \pm 6$ & $96 \pm 10$ & $66 \pm 3$ & 88 & $94 \pm 22$ & $111 \pm 6$ & $88 \pm 5$ \\
\hline & $n<50$ years & 2 & 4 & 0 & 29 & 0 & 0 & 0 & 9 \\
\hline & $n$ 50-80 years & 4 & 7 & 7 & 53 & 0 & 1 & 2 & 9 \\
\hline & $n>80$ years & 1 & 8 & 10 & 27 & 1 & 2 & 12 & 28 \\
\hline & range & $25-81$ & $38-114$ & $57-219$ & $25-219$ & $88-88$ & $64-136$ & $71-146$ & $32-163$ \\
\hline \multirow[t]{5}{*}{ Cohort class 3} & Mean \pm SE & $71 \pm 13$ & $70 \pm 7$ & $110 \pm 5$ & $89 \pm 3$ & - & $94 \pm 8$ & $132 \pm 12$ & $105 \pm 7$ \\
\hline & $n<50$ years & 2 & 2 & 0 & 11 & 0 & 0 & 0 & 2 \\
\hline & $n 50-80$ years & 2 & 6 & 7 & 46 & 0 & 2 & 0 & 5 \\
\hline & $n>80$ years & 3 & 4 & 41 & 74 & 0 & 5 & 10 & 25 \\
\hline & range & $26-120$ & $45-126$ & $52-175$ & $26-175$ & 0 & $59-123$ & $81-191$ & $27-191$ \\
\hline \multirow[t]{5}{*}{ All classes } & Mean \pm SE & $55 \pm 6$ & $71 \pm 4$ & $105 \pm 4$ & $71 \pm 2$ & $67 \pm 9$ & $87 \pm 7$ & $118 \pm 6$ & $86 \pm 4$ \\
\hline & $n<50$ years & 12 & 7 & 1 & 90 & 2 & 2 & 0 & 23 \\
\hline & $n 50-80$ years & 6 & 14 & 15 & 111 & 1 & 3 & 2 & 24 \\
\hline & $n>80$ years & 4 & 13 & 53 & 107 & 3 & 9 & 25 & 61 \\
\hline & range & $25-120$ & $38-126$ & $42-219$ & $25-220$ & $42-88$ & $44-136$ & $71-191$ & $26-191$ \\
\hline
\end{tabular}

${ }^{a}$ Includes only sites of known disturbance origin.

${ }^{\mathrm{b}}$ Includes sites of known and unknown disturbance origin.

Table 6. Means of snag and downed wood variables in cohort classes of boreal mixedwood stands in northeastern Ontario $(n=308)$ and results from Analysis of Variance and Tukey's tests comparing the rank-transformed variables among classes

\begin{tabular}{|c|c|c|c|c|c|c|c|c|c|c|}
\hline \multirow{2}{*}{$\begin{array}{l}\text { Deadwood } \\
\text { variable }^{\mathrm{a}}\end{array}$} & \multicolumn{2}{|c|}{$\begin{array}{l}\text { Cohort class } 1 \\
(n=68 ; n=6)^{b}\end{array}$} & \multicolumn{2}{|c|}{$\begin{array}{c}\text { Cohort class } 2 \\
(n=109 ; n=19)^{\mathrm{b}}\end{array}$} & \multicolumn{2}{|c|}{$\begin{array}{c}\text { Cohort class } 3 \\
(n=131 ; n=29)^{\mathrm{b}}\end{array}$} & \multirow{2}{*}{$\begin{array}{l}\text { ANOVA } \\
\text { P value }\end{array}$} & \multirow{2}{*}{$\begin{array}{c}\text { Class } 1 \\
\text { vs. } \\
\text { Class } 2^{\mathfrak{c}}\end{array}$} & \multirow{2}{*}{$\begin{array}{c}\text { Class } 2 \\
\text { vs. } \\
\text { Class } 3^{\mathrm{c}}\end{array}$} & \multirow{2}{*}{$\begin{array}{c}\text { Class } 1 \\
\text { vs. } \\
\text { Class } 3^{\mathrm{c}}\end{array}$} \\
\hline & Mean & Std. dev. & Mean & Std. dev. & Mean & Std. dev. & & & & \\
\hline nsnag_1 & 1.84 & 6.57 & 3.08 & 13.04 & 11.39 & 21.14 & $<.0001$ & - & * & * \\
\hline nsnag_m & 4.41 & 12.17 & 20.64 & 43.27 & 20.99 & 30.35 & 0.0001 & * & - & * \\
\hline nsnag_s & 6.17 & 11.62 & 34.5 & 51.84 & 20.39 & 35.42 & $<.0001$ & * & * & * \\
\hline nsnagTOT & 12.42 & 21.34 & 58.23 & 85.21 & 52.77 & 60.34 & $<.0001$ & * & - & * \\
\hline osnag_1 & 18.5 & 34.4 & 12.99 & 27.37 & 21.27 & 32 & 0.0251 & - & * & - \\
\hline osnag_m & 12.43 & 26.77 & 24.67 & 36.27 & 28.07 & 38.15 & 0.0007 & * & - & * \\
\hline osnag_s & 8.97 & 19.65 & 24.19 & 36.7 & 14.89 & 29.49 & 0.0004 & * & * & - \\
\hline osnagTOT & 39.9 & 52.79 & 61.84 & 66.84 & 64.23 & 61.01 & 0.0048 & * & - & * \\
\hline newDWD & 44.48 & 17.97 & 57.72 & 42.75 & 140.75 & 86.41 & 0.0002 & - & * & * \\
\hline oldDWD & 23.6 & 20.9 & 11.23 & 10.37 & 24.72 & 16.77 & 0.009 & - & * & - \\
\hline
\end{tabular}

a Deadwood variables: large, medium, small, and total number of snags in early stages of decay, respectively (nsnag_l, nsnag_m, nsnag_s, nsnagTOT); large, medium, small, and total number of snags in late stages of decay (osnag_l, osnag_m, osnag_s, osnagTOT); downed wood in early (newDWD) and late (oldDWD) stages of decay. See text for additional details.

b The first sample size in parenthesis is for snag variables; the second is for downed wood variables.

' Results from Tukey's range tests where " " indicates a significant difference at $\alpha=0.05$. 
With respect to associations between cohort class and disturbance history, unlogged sites represented more than half of the total number of mixedwood sites of known origin and the majority of these $(\sim 70 \%)$ were in cohort class 3 . The majority of horse-logged mixedwood sites were in cohort classes $2(56 \%)$ and $3(35 \%)$, and only three of these sites (9\%) were in cohort class 1 . Surprisingly, mechanically logged mixedwood sites were almost evenly distributed among the three cohort classes (Table 5). For black spruce forests, unlogged black spruce sites were most frequently in cohort class 2 (52\%), although many $(37 \%)$ were also in cohort class 3 . Horse-logged black spruce sites were most often in cohort class 3 (50\%). Mechanically logged black spruce sites showed the strongest association with cohort class in that 5 of 6 were in cohort class 1 and none in class 3 (Table 5). Likelihood ratio tests indicated that disturbance history was significantly associated with cohort class membership in both forest types $(p<0.0001$ and $p<0.0029$ for mixedwoods and black spruce, respectively).

\section{Deadwood variables}

For mixedwoods, examination of means and results from Tukey's tests indicated three main patterns of variation in deadwood as a function of cohort class (Table 6). Large fresh snags and fresh DWD were relatively common in cohort class 3 stands compared to cohort class 1 and class 2 stands. Small fresh and well-decomposed snags were relatively common in cohort class 2 stands compared to the other two cohort classes, whereas large well-decomposed snags and DWD in later stages of decay were relatively rare in these stands. The remaining variables (medium-sized and total fresh, and medium-sized and total well-decomposed snags) were relatively rare in cohort class 1 stands compared to cohort class 2 and 3 stands.

Black spruce sites revealed three main patterns that showed similarities with the mixedwood results (Table 7). Medium-sized, well-decomposed snags and both fresh and well-decomposed large snags tended to be relatively common in cohort class 3 stands compared to cohort class 1 and class 2 stands. Well-decomposed DWD, although not significant, tended to be more common in cohort class 1 and class 3 stands than in cohort class 2 stands. Features that were relatively common in cohort class 2 and class 3 stands, but rarer in cohort class 1 stands, included small fresh and well-decomposed snags, total number of fresh and well-decomposed snags, and medium-sized fresh snags. Fresh DWD showed the same pattern, but was not significant.

\section{Discussion}

Using a broad suite of variables that focused on the size variability, density, and canopy stratification of live trees, we found that major axes of structural variation supported the threecohort MFM model of Bergeron et al. (1999). Variation in stand age and deadwood features among the structural cohort classes supported the idea that the classes reflected progressive stages of stand development following stand-replacing disturbances. Stands of clearcut harvest origin were more frequently associated with cohort classes 1 and 2, supporting conclusions of previous studies that even-aged management tends to simplifies boreal forest stand structure (Sturtevant et al. 1997, Pedlar et al. 2002).

The diameter distributions of our cohort classes coincided well with expectations based on progressive stages of stand development (Nguyen 2000, Harvey et al. 2002). Measures such as diameter class richness, range, and diversity that are associated with well-developed, uneven-aged, and old-growth stand structures (Boucher et al. 2003, 2006; Kneeshaw and Gauthier 2003; Harper et al. 2005) increased significantly with structure class in both forest types. Decreases in total tree densities and related trends in relative tree densities by size class in cohort classes 1 through 3 in both forest types also supported a developmental basis for our cohort classifications (Lee et al. 2000, Brassard and Chen 2006, Bauhus et al. 2009).

Differences in the vertical arrangement of canopy structure presumably reflected developmental aspects as well. Interestingly, in black spruce stands, crown class diversity and evenness were greatest in cohort class 3 , whereas in mixedwoods they were greatest in cohort class 2; one or both of these variables were included in the classification functions in both forest types. These differences may reflect different structural development pathways in the two forest types. In lowland boreal black spruce forests, where successional changes in tree species composition are virtually absent, the ongoing recruitment of black spruce primarily through layering causes these stands to develop increasingly complex vertical canopy structures at relatively small spatial scales (Harper et al. 2002, 2005). This is not necessarily the case in boreal mixedwoods, where canopy succession often involves the replacement of large, shade-intolerant pioneer species with generally smaller-stature but more shade-tolerant spruce and fir in larger canopy openings (Chen and Popadiouk 2002). Vertical stratification and height diversity measured at the scale of growth plots (i.e., $400 \mathrm{~m}^{2}$ ) might be expected to consequently decrease in boreal mixedwoods later in succession (Harper et al. 2002, Brassard et al. 2008).

One goal of this study was to develop a classification method that did not rely upon an initial visual classification of stand diameter distributions (Nguyen 2000, Boucher et al. 2003), which we achieved through the combined use of principal component and cluster analyses. At the same time, our methods still had a subjective element with respect to our grouping of clusters.

A related point concerns the potential value of cohort classifications that rely on multiple variables that co-vary with differences in diameter distributions. Here, we demonstrate that structural cohort classifications can be augmented by including additional structural attributes that might be expected to co-vary with tree diameters, such as variation in stem densities and the vertical arrangement of forest canopies, potentially better reflecting changes in structural complexity associated with multi-cohort development (Bergeron et al. 2001, Gauthier et al. 2002). Multivariate approaches that consider structural attributes in addition to those related to stem diameters may be required to assess stand structural complexity that, by definition, considers multiple structural features (McElhinny et al. 2005). In this study, the majority of classification variables were significantly different among the three cohort classes, and classification functions for both forest types included a combination of tree diameter, tree density, and variables related to canopy stratification. Studies that infer the most well-developed, uneven-aged stand structures using diameter diversity alone (e.g., Boucher et al. 2006) probably provide only a partial assessment of complex multi-cohort stand structures (Zenner 2000, Boucher et al. 2003, McElhinny et al. 2005).

Associations between the cohort classes and the individual 
Table 7. As table 6 except that results are for boreal black spruce sites.

\begin{tabular}{|c|c|c|c|c|c|c|c|c|c|c|}
\hline \multirow{3}{*}{$\begin{array}{l}\text { Deadwood } \\
\text { variable }^{1}\end{array}$} & \multirow{2}{*}{\multicolumn{2}{|c|}{$\frac{\text { Cohort class } 1}{(n=30 ; n=7)^{2}}$}} & \multirow{2}{*}{\multicolumn{2}{|c|}{$\frac{\text { Cohort class } 2}{(n=46 ; n=7)^{2}}$}} & \multicolumn{3}{|c|}{ Cohort class 3} & \multirow{3}{*}{$\begin{array}{c}\text { Class } 1 \\
\text { vs. } \\
\text { Class } 2^{3}\end{array}$} & \multirow{3}{*}{$\begin{array}{c}\text { Class } 2 \\
\text { vs. } \\
\text { Class } 3^{3}\end{array}$} & \multirow{3}{*}{$\begin{array}{c}\text { Class } 1 \\
\text { vs. } \\
\text { Class } 3^{3}\end{array}$} \\
\hline & & & & & \multicolumn{2}{|c|}{$(n=32 ; n=7)^{2}$} & \multirow{2}{*}{$\frac{\text { ANOVA }}{\text { P value }}$} & & & \\
\hline & Mean & Std. dev. & Mean & Std. dev. & Mean & Std. dev. & & & & \\
\hline nsnag_1 & 0.00 & 0.00 & 0.00 & 0.00 & 1.82 & 6.26 & 0.0265 & - & * & - \\
\hline nsnag_m & 0.83 & 4.56 & 11.23 & 20.50 & 18.75 & 23.47 & 0.0001 & * & - & * \\
\hline nsnag_s & 5.94 & 12.52 & 52.36 & 73.25 & 36.72 & 41.79 & $<.0001$ & * & - & * \\
\hline nsnagTOT & 6.78 & 14.51 & 63.59 & 82.67 & 57.29 & 56.27 & $<.0001$ & * & - & * \\
\hline osnag_1 & 0.83 & 4.56 & 0.18 & 1.23 & 4.69 & 13.38 & 0.1109 & - & - & - \\
\hline osnag_m & 2.78 & 10.11 & 7.68 & 16.13 & 22.92 & 32.72 & 0.0002 & - & * & * \\
\hline osnag_s & 2.06 & 6.37 & 23.37 & 39.03 & 19.79 & 21.66 & 0.0001 & * & - & * \\
\hline osnagTOT & 5.67 & 11.98 & 31.23 & 42.41 & 47.40 & 43.86 & 0.0000 & * & - & * \\
\hline newDWD & 10.87 & 12.54 & 25.45 & 31.32 & 26.96 & 19.87 & 0.1067 & - & - & - \\
\hline oldDWD & 3.14 & 5.42 & 1.02 & 1.96 & 3.70 & 9.12 & 0.9030 & - & - & - \\
\hline
\end{tabular}

${ }^{1}$ See Table 6 for variable descriptions.

${ }^{2}$ The first sample size in parenthesis is for snag variables; the second is for downed wood variables.

${ }^{3}$ Results from Tukey's range tests where “*” indicates a significant difference at $\alpha=0.05$.

analysis variables were largely consistent between the two forest types, suggesting that the approach may be transferrable to other forest types. However, cohort class 2 and class 3 black spruce sites shared a similar range of variation along the main tree size and density-related gradient of structural variability (axis one), whereas the two corresponding mixedwood cohort classes did not. Thus, the characteristic cohort class diameter distribution patterns proposed by Nguyen (2000) appeared to better fit mixedwoods than black spruce forests. Not surprisingly, tree size was less variable in black spruce than in mixedwood stands, which might have made diameter distribution-related differences in black spruce harder to detect (Harper et al. 2005, Boucher et al. 2006).

As hypothesized, stand age increased significantly with cohort class in support of the MFM conceptual model (Bergeron et al. 1999, Nguyen 2000, Harvey et al. 2002). However, counter to expectations, stand ages were highly variable within, and overlapped extensively among cohort classes in both forest types. For young stands, the reality is that both fire and, to a lesser degree, harvesting rarely eliminates all pre-existing stand structures (McRae $e t$ al. 2001, Franklin et al. 2002). Instead, both these "stand-replacing" disturbance types often result in varying degrees of living and dead residual structure that may persist (locally rather than generally) as structural and biological legacies (McRae et al. 2001, Greif and Archibold 2000, Pedlar et al. 2002). In addition, differences in the frequency and severity of non stand-replacing disturbance events may result in stands of similar age exhibiting a wide range of stand structures (Bouchard et al. 2006, Brassard and Chen 2006).

Significant differences in the frequencies of cohort classes between managed and natural stands in both mixedwoods and black spruce forests provided support for the hypothesis that past logging has simplified forest structure, either because managed forests tended to be younger or because logging resulted in reduced structural complexity even when controlling for age. A large majority of natural-origin mixedwood stands were in cohort class 3 , and mechanically logged mixedwood sites were more frequently associated with cohort class 1 compared to horse-logged and natural-origin mixedwood stands. At the same time, mechanically logged mixedwoods were almost evenly distributed among cohort classes. The presence of large veteran trees in growth plots offers the most likely explanation for relatively young mechanically logged mixedwood stands exhibiting complex multi-cohort structures. Given that harvesting in the region has historically focussed on spruce (Radforth 1987, Lefort et al. 2002), it is not unreasonable to assume that the quantity of residual trees following harvests was higher in mixedwood forest types than that in black spruce forests, which could explain why results for mechanically logged sites were so different between forest types. Based on the frequency of class 2 and class 3 structures among horse- and mechanically logged sites, it is evident that even-aged management in some cases may still allow for the maintenance of complex multi-cohort structures. These results suggest that the purposeful manipulation of stand structure can be used to emulate complex multi-cohort stand structures, given that we found stands that exhibited complex diameter structures at relatively young ages (i.e., $<50$ years old) in boreal mixedwoods, and at young-to-intermediate ( $\leq 80$ years old) ages in lowland black spruce forests.

Abundance and diversity of most deadwood features varied significantly among the cohort classes and trends were consistent with general expectations under multi-cohort stand development. In both forest types small snags in both early and late stages of decay were most common in cohort class 2 , most likely as a result of self-thinning (Chen and Popadiouk 2002). Snags produced through competition-induced mortality during the stem exclusion development stage tend to be small, whereas during the canopy transition stage of development, proportionally more snags are the result of age-related tree mortality and thus become larger in size (Lee et al. 1997, Chen and Popadiouk 2002, Harper et al. 2005). Cohort class 2 sites therefore appeared to represent a combination of late stem exclusion and early canopy transition stages of development as the pioneering age cohort of trees presumably died and were replaced from below. Such conditions 
are recognized in the three-cohort model as the onset of the transition to cohort 2 stand structure (Harvey et al. 2002).

Medium and large snags, especially heavily decayed ones, were found consistently in greater abundances in cohort class 3 than class 2 in both forest types, in accord with expectations for late-successional stands (Chen and Popadiouk 2002, Harper et al. 2005, Brassard and Chen 2006). Small snags in both early and late stages of decay were also considerably more abundant in cohort class 3 than in class 1 . These various differences are consistent with snag dynamics reported in the literature, specifically: 1) snags in the gap dynamics development stage are largely produced by non-stand-replacing disturbances such as insect attacks, disease, senescence and damage by ice, snow, and wind that tend to affect large trees and 2) because these factors are not necessarily size-specific, a greater range of snag diameters is affected in older stands (Clark et al. 1998, Chen and Popadiouk 2002, Brassard and Chen 2006).

Despite the relatively small number of stands sampled for downed wood, differences among the cohort classes also provided evidence of progressive stages of stand development. The volume of downed logs has generally been found to follow a U-shaped distribution in relation to stand age (Lee et al. 1997, Sturtevant et al. 1997, Clark et al. 1998). Logs of disturbance origin contribute to high volumes in young stands that decline over time due to decay, whereas post-disturbance inputs remain low until stands reach maturity and then increase exponentially as stands continue to age (Sturtevant et al. 1997, Brassard and Chen 2006). The volume of fresh downed wood increased with cohort class in both forest types, especially in mixedwoods, as expected given increases in new log deposition that accompany the replacement of a pioneer cohort of trees by subsequent tree cohorts.

Interestingly, despite the inclusion of both logged and natural-origin stands in the deadwood analyses, the anticipated trends based on studies of natural deadwood dynamics emerged. Clearcutting, the historical and most widely-used approach to management in the region, is known to significantly influence deadwood dynamics by disrupting the availability and production of deadwood for a substantial period of time (Sturtevant et al. 1997, Sippola et al. 1998). However, just as disturbance residuals likely influenced stand age estimates in this study, they may also have contributed to relatively high snag and log abundances in some previously logged stands, rendering logging effects on deadwood features more difficult to detect, particularly in the mixedwood forest types.

\section{Management Implications}

We found that many harvest and natural-origin stands exhibited similar multi-cohort stand structures, and that both natural and harvest origin stands were represented in all three cohort classes in both forest types that we studied. Thus, it appears that our cohort classifications were based more on structural differences among cohort classes than on differences between logged and unlogged stands, and may therefore prove especially useful to support the application of MFM in managed forest landscapes that encompass both natural and previously harvested stands.

The lack of detailed structural information in FRI data remains an impediment to the integrated planning and operational application of multi-cohort management in Ontario (Harvey et al. 2002, Groot et al. 2004). Although the classifications developed in this study did not directly address changes in species composition that often accompany succession, they did address the need to better quantify existing multi-cohort-related variation in stand structures. Groot et al. (2004) suggested that the lack of detailed structural information in FRI may be compensated by the fact that forest structural characteristics can be correlated to FRI attributes such as stand age, species composition, and site quality. Although we did not undertake such an analysis here, our cohort classification approach could be used to test for such correlations; indeed, data from Ontario's relatively extensive Growth and Yield Plot Network could be used to extend our classification approach to the full suite of forest unit types used in forest management planning in boreal Ontario. Combined with the best available time-sincefire and composition data, such an extension could be used to undertake measurement of proportional representation of the three cohort classes at the forest level and support forecasting of the future distribution of cohort classes under multi-cohort forest management, two key requirements of planning in support of MFM (Groot et al. 2004). Even for early successional forest types such as poplar- or jack pine-dominated stands that might be considered first cohort stands according to the conceptual model (Bergeron et al. 2002), a means to measure and partition structural variability might support other management objectives, such as the detailed characterizations of wildlife habitat. Classifications such as ours that consider a broad suite of stand structural variables, which represent a diverse set of potential niches, may perform better as a coarse-filter predictor for wildlife communities than age-based species-habitat associations that infer that certain structural conditions exist solely as a function of stand age.

Operationally, structural cohort classifications such as those presented here might also be used to gauge the success of silvicultural interventions to manipulate multi-cohort structure; for example, by establishing temporary plots during pre-harvest surveys to attribute cohort class to stands using empirical data, and following harvest at different time intervals to evaluate the success of silvicultural interventions in emulating increasingly complex cohort class 2 and cohort class 3 stand structures.

\section{Conclusions}

Our study supports the association of even-sized, irregular, and inverse-J diameter structure types with progressive stages of stand development in both mixedwood and black spruce forests of northeastern Ontario. These diameter patterns coincided in multivariate analyses with a wide array of structural features related to tree size, density, and canopy stratification. Overall, developmental aspects of our cohort classifications were also supported by variation in stand age and, to a large extent, variation in deadwood features among cohort classes in both forest types. The lack of significant differences in age and deadwood features between cohort class 2 and class 3 black spruce stands, however, calls into question the degree to which structural complexity is age-related in this forest type; instead, it may better reflect other features, such as site productivity. Similarities in the mixedwood and black spruce classification results suggest that our structure-based three-cohort classification is broadly applicable and may be used to bridge strategic and site-specific operational planning in support of an integrated stand-and-landscape approach to multi-cohort forest management (Harvey et al. 2002, Groot et al. 2004). 


\section{Acknowledgements}

We would like to thank several organizations for their support of this and associated research: Ontario's Forestry Futures Trust, Ontario Ministry of Natural Resources, Ontario Centres of Excellence, NSERC, Sustainable Forest Management Network, Lake Abitibi Model Forest, Canadian Forest Service, Tembec Inc., KBM Resources Group Inc., Forest Ecosystem Science Co-op, Forestry Research Partnership, Canadian Institute of Forestry, and Faculty of Forestry at the University of Toronto. We are particularly indebted to the data and guidance provided by the Growth and Yield Unit of the Ontario Terrestrial Assessment Program. Funding for Ben Kuttner was provided by the Faculty of Forestry at U of T, NSERC, Ontario Graduate Scholarships in Science and Technology, the Ontario Centres of Excellence, and the Canadian Forest Service. Lastly, we would especially like to thank John Pineau for his vision and role in helping to organize this issue of The Forestry Chronicle and Brian Harvey and two anonymous reviewers for helpful comments on an earlier draft of the paper.

\section{References}

Abernethy, R. 1996. The New Weibull Handbook: Reliability \& Statistical Analysis for Predicting Life, Safety, Survivability, Risk, Cost and Warranty Claims, 4th edition. Robert B Abernethy, North Palm Beach, FL. $310 \mathrm{p}$.

Bauhus, J., K. Puettmann and C. Messier. 2009. Silviculture for oldgrowth attributes. For. Ecol. Manage. 258: 525-537.

Bergeron, Y., P. Drapeau, S. Gauthier and N. Lecomte. 2007. Using knowledge of natural disturbances to support sustainable forest management in the northern Clay Belt. For. Chron. 83: 326-337.

Bergeron, Y., S. Gauthier, V. Kafka, P. Lefort and D. Lesieur. 2001. Natural fire frequency for the eastern Canadian boreal forest: consequences for sustainable forestry. Can. J. For. Res. 31: 384-391.

Bergeron, Y. and B. Harvey. 1997. Basing silviculture on natural ecosystem dynamics: an approach applied to the southern boreal mixedwood forest of Quebec. For. Ecol. Manage. 92: 235-242.

Bergeron, Y., B. Harvey, A. Leduc and S. Gauthier. 1999. Forest management guidelines based on natural disturbance dynamics: Stand and forest-level considerations. For. Chron. 75: 49-54.

Bergeron, Y., A. Leduc, B.D. Harvey and S. Gauthier. 2002. Natural fire regime: a guide for sustainable management of the Canadian boreal forest. Silva Fennica 36: 81-95.

Boucher, D., L. De Grandpré and S. Gauthier. 2003. Développement d'un outil de classification de la structure des peuplements et comparaison de deux territoires de la pessière à mousses du Québec. For. Chron. 79(2): 318-328.

Boucher, D., S. Gauthier, and L. De Grandpré. 2006. Structural changes in coniferous stands along a chronosequence and a productivity gradient in the northeastern boreal forest of Quebec. Ecoscience. 13(2): 172-180.

Bouchard, M., D. Kneeshaw and Y. Bergeron. 2006. Forest dynamics after successive spruce budworm outbreaks in mixedwood forests. Ecology 87(9): 2319-2929.

Brassard, B.W. and H.Y.H. Chen. 2006. Stand structural dynamics of North American boreal forests. Crit. Rev. Plant Sci. 25:37-59.

Brassard, B.W., H.Y.H. Chen, J.R. Wang and P.N. Duinker. 2008. Effects of time since stand replacing fire and overstory composition in the boreal forest of central Canada. Can. J. For. Res. 38: 52-62.

Chapman, L.J. and M.K. Thomas. 1968. The Climate of Northern Ontario. Climatological Studies, No. 6, Dept. Transport, Meteorological Branch, Ottawa.

Chen, H.Y.H. and R.V. Popadiouk. 2002. Dynamics of North American boreal mixedwoods. Env. Rev. 10: 137-166.

Clark, D. F., D.D. Kneeshaw, P.J. Burton and J.A. Antos. 1998. Coarse woody debris in sub-boreal spruce forests of west-central British Columbia. Can. J. For. Res. 28: 284-290.
Crins, W.J, P.A. Gray and P.W.C. Uhlig. 2006. The Ecosystems of Ontario, Part 1: Ecozones and Ecoregions. Ontario Ministry of Natural Resources, Peterborough. [Draft]. November 2006. 56 p.

Environment Canada. 1993. Canadian Climate Normals 1961-1990 [online]. Canadian Climate Program, Atmospheric Environment Service, Downsview, ON. Available at http://climate.weatheroffice.ec.gc.ca [Accessed May 17, 2007].

Franklin J.F. et al. 2002. Disturbances and structural development of natural forest ecosystems with silvicultural implications, using Douglas-fir forests as an example. For. Ecol. Manage. 155(1-3): 399-423.

Gauthier, S., P. Lefort and P. Drapeau. 2002. Time since fire map, ageclass distribution and forest dynamics in the Lake Abitibi Model Forest. Natural Resources Canada, Canadian Forest Service, Laurentian Forestry Centre, Sainte-Foy, QC. Inf. Rep.LAU-X-125E. 9 p.

Greif, G.E. and O.W. Archibold. 2000. Standing-dead tree component of the boreal forest in central Saskatchewan. For. Ecol. Manage. 131: 37-46.

Groot, A., S. Gauthier and Y. Bergeron. 2004. Stand dynamics modelling approaches for multi-cohort management of eastern Canadian boreal forests. Silva Fenn. 38(4): 437-448.

Harper, K., Y. Bergeron, S. Gauthier and P. Drapeau. 2002. Post fire development of canopy structure and composition in black spruce forests of Abitibi, Quebec: A landscape scale study. Silva Fenn. 36(1): 249-263.

Harper, K., Y. Bergeron, P. Drapeau, S. Gauthier and L. De Grandpré. 2005. Structural development following fie in black spruce boreal forest. For. Ecol. Manage. 206: 293-306.

Harvey, B.D., A. Leduc, S. Gauthier and Y. Bergeron. 2002. Standlandscape integration in natural disturbance-based management of the southern boreal forest. For. Ecol. Manage. 155: 369-385.

Hayden, J. 2003. Ontario Growth and Yield Program Permanent Growth Plot Reference Manual. [Draft]. Ontario Ministry of Natural Resources, Ontario Forest Research Institute, Sault Ste. Marie, ON.

Hayden, J., J. Kerley, D. Carr, T. Kenedi and J. Hallarn. 1995. Ontario Forest Growth and Yield Program Field Manual. Ontario Ministry of Natural Resources. Ontario Forest Research Institute. Sault Ste. Marie, ON. 95 p.

Kneeshaw, D. and S. Gauthier. 2003. Old growth in the boreal forest: A dynamic perspective at the stand and landscape level. Env. Rev. 11: S99-S114.

Kuttner, B.G. 2006. Description, characterization, and identification of stand structure classes in northeastern Ontario: the application of multi-cohort concepts in the classification of stands from four forest types to cohorts. Technical report \# 3. Lake Abitibi Model Forest. 45 p. Lecomte, N. and Y. Bergeron. 2005. Successional pathways on different surficial deposits in the coniferous boreal forest of the Quebec claybelt. Can. J. For . Res. 35: 1984-1995.

Lee, P.C., S. Crites, M. Nietfeld, H. Van Nguyen and J.B. Stelfox. 1997. Characteristics and origins of deadwood material in aspen-dominated boreal forests. Ecol. Appl. 7: 691-701.

Lee, P., S. Hanus and B. Grover. 2000. Criteria for estimating old growth in boreal mixedwoods from standard timber inventory data. For. Ecol. Manage. 129: 25-30.

Lefort, P., B. Harvey, J. Parton and G.K.M. Smith. 2002. Synthesizing knowledge of the Claybelt to promote sustainable forest management. For. Chron. 78 (5): 665-671.

Legendre, P. and L. Legendre. 1998. Numerical Ecology. Elsevier Science B.V., New York.

Mackey, B.G., D.W. McKenney, Y.-Q. Yang, J.P. McMahon and M.F. Hutchinson. 1996. Site regions revisited: a climatic analysis of Hills' site regions for the Province of Ontario using a parametric method. Can. J. For. Res. 26: 333-354.

Marshall, P.L., G. Davis and V.M. LeMay. 2000. Using Line Intersect Sampling for Coarse Woody Debris. B.C. Forest Service. Technical Report TR-003. Nanaimo, BC. 
Maser, C., G. Anderson, K. Cromack Jr., J.T. Williams and R.E. Martin. 1979. Dead and downed woody material. In J.W. Thomas (ed.). Wildlife habitats in managed forests: the Blue Mountains of Oregon and Washington. Agriculture Handbook, No. 553. U.S. Department of Agriculture, Washington, DC.

Maxie, A.J. , K.F. Hussey, S.J. Lowe, K.R. Middel, B.A. Pond, M.E. Obbard and B.R. Patterson. 2010. A comparison of forest resource inventory, provincial land cover maps, and field surveys for wildlife habitat analysis in the Great Lakes -St. Lawrence forest. For. Chron. 86 (1): 77-85.

McElhinny, C., P. Gibbons, C. Brack and J. Bauhus. 2005. Forest and woodland stand structural complexity: Its definition and measurement. For. Ecol. Manage. 218: 1-24.

McRae, D.J., L.C. Duchesne, B. Freedman, T.J. Lynham and S. Woodley. 2001. Comparisons between wildfire and forest harvesting and their implications in forest management. Environmental Reviews 9: 223-260.

Miller, R.J. 1994. Stem Analysis Measurement System (SAMSYSTEM). Stem Analysis Measurement Increment Core Capture Version 1.1. Ontario Forest Research Institute, Ontario Ministry of Natural Resources, Sault Ste. Marie, ON.

Nguyen, T. 2000. Classification of Northern Abitibi's spruce-moss forest stands according to their internal structure. Preliminary report to the Quebec Ministry of Natural Resources. July 2000. 24 p.

Pedlar, J.H., J.L. Pearce, L.A. Venier and D.W. McKenney. 2002. Coarse woody debris in relation to disturbance and forest type in boreal Canada. For Ecol. Manage. 158: 189-194.

Peres-Neto, P.R., D.A. Jackson and K.M. Somers. 2005. How many principal components? stopping rules for determining the number of non-trivial axes revisited. Comput. Stat. Data An. 49 (2005): 974 - 997.
Pinto, F., M. Ter-Mikaelian, J. Sobze and D. Rouillard. 2007. A method to validate stand attributes in a forest resource inventory: A case study in Nipissing Forest, Ontario. Ontario Forest Research Institute. Forest research report no. $166.27 \mathrm{p}$.

Radforth, I. 1987. Bushworkers and Bosses: Logging in Northern Ontario, 1900-1980. University of Toronto Press, Toronto. 336 p.

Rowe, J.S. 1972. Forest regions of Canada. Can. Dep. Environ., Can. For. Serv., Ottawa, ON. Publ. No. 1300. 172 p.

Sippola, A.-L., J. Siitonen, and R. Kallio. 1998. Amount and quality of coarse woody debris in natural and managed coniferous forests near the timberline in Finnish Lapland. Scand. J. Forest Res. 13: 204-214.

Sokal, R.R. and F.J. Rolf. 1995. Biometry: the principles and practice of statistics in biological research. 3rd ed. W.H. Freeman, New York. $887 \mathrm{p}$.

Sturtevant, B.R., J.A. Bissonette, J.N. Long and D.W. Roberts. 1997. Coarse woody debris as a function of age, stand structure, and disturbance in boreal Newfoundland. Ecol. Appl. 7: 702-712.

Thompson, I., S. Maher, D. Rouillard, J. Fryxell and J. Baker. 2007. Accuracy of forest inventory mapping: Some implications for boreal forest management. For. Ecol. Manage.. 252: 208-221.

Watt, W. R., J. Parton, S. Vasiliauskas, H. Chen, G. Lucking and N. Houle. 2003. Standard forest units for northeastern Ontario boreal forests. OMNR Northeast Science \& Information Info. Rep. [Draft].

Zenner, E.K. 2000. Do residual trees increase structural complexity in Pacific Northwest coniferous forests? Ecol. Appl. 10: 800- 810. 